\title{
Experiences as Consumers: In-Depth Interview of Thai Students Studying in Korea
}

This study aims to understand the experiences as consumers of Thai students studying in Korea. "Study Korea Project" which is a drive to globalize local universities by attracting more oversea students as a pull factor, and economic growth, values on education and Hallyu as push factors contribute to the increase the number of Thai students in Korea. In order to understand the experiences of Thai students as consumers studying in Korea, individual interviews were conducted. A total of 5 participants were asked about meaning of consumption in everyday life in Korea or any changes in consumption behavior compared to living in Thai. Three themes were identified through wholistic and selective approaches. First, all participants in the study said that they were surprised because of high living expense in Korea. Consequently, survival itself is too much for them and they have become more conscious of prices of goods. Secondly, since most participants in this study can control their own budget, they feel some degree of freedom and power of control of their own lives. This experience may help them to accomplish their developmental tasks during the transition to adulthood. Thirdly, they are easily imbued with Korean consumer culture. It causes various conflicts between buying and notbuying, or friends gathering and saving money. Sometimes it makes them in stuck excessive consumption and financial problems. For a deeper understanding of oversea students lives in Korea as consumers, further studies should take into consideration of not only their culture of origins, but also misconceptions that have accumulated around these students.

\footnotetext{
Associate Professor, Department of Consumer Studies, Ewha Womans University, Seoul, Korea (hjcheon@ewha.ac.kr)

*M.A. student, Department of Consumer Studies, Ewha Womans University, Seoul, Korea
}

Key Words: Thai students, oversea students in Korea, consumer experiences
Korea has known as one of active countries that send their students abroad as their number continuous to grow enormously. The number of Korean students who study abroad at the university level increased from 149,933 in 2001 to 251,887 in 2010 (Ministry of Education, Science and Technology, 2010). Recently in Korea, it is a national policy to recruit inbound foreign students through so called 'Study Korea Project.' During the 1990s, the number of foreign students studying in Korea stood at about 2,000 and varied little during those years. Since 2000 , however, the number dramatically increased. In 2010,83,842 foreign students were studying in Korea, and this is nearly six times more than those registered in 2001 (Ministry of Education, Science and Technology, 2010). This rapid increase in foreign students since 2000 occurred at the same time that many universities in Korea make efforts toward greater globalization.

Globalization has precipitated substantial influences on higher education. As Levin (2001) points out that "with emphasis upon international competitiveness, economic globalization is viewed as moving postsecondary institutions into a business-like orientation, with its attendant behaviors of efficiency and productivity" (p. 239). Specific behaviors are the recruitment of students from other countries, the delivery of college curriculum in other nations, and the inculcation of others' values. One outward sign of Korean universities' continuing globalization is the increased enrollment of foreign-national students. 
Over $70 \%$ of Korean students studying abroad went to English-speaking countries, whereas approximately $60 \%$ of foreign students studying in Korea were from neighboring Asian countries (Kang, 2009). The top three countries send the most students to Korea are China, Japan, and Vietnam. Especially, 70\% of these students are from China. According to Kang's survey (2009), China, Philippines, Vietnam, Singapore, and Thailand students in order selected Korea to be very preferable country to study abroad. However, not much is known about foreign students' lives in Korea, and only available their nationality and major of study through national statistics (Ahn, 2009). Moreover, most research about foreign students in Korea has been focused on recruiting strategies and foreign students' adjustment, especially Chinese students' academic, psychological, and cultural stresses (Cui, 2008; Lee \& Kim, 2009; Lim, 2009; Song \& Li, 2008). Other Asian students except Chinese did not get attention merely because of their relatively small number. Considering these circumstances, it is hard to find a clue to maximize foreign students' inducement policy. In addition, quantitative expansion is followed by various side effects and management problem, and it is already criticized that recent inducement of foreign students is not as good as it looks. Therefore, it requires more in-depth study about inbound students' lives in Korea that has not yet been dealt with seriously in academic area.

Different Asian countries have different cultural values and historical background. Consequently, foreign students studying in Korea experience different cultural encounters according to their origin of culture. In this study, Thailand students are selected. Because the number of Thai students studying Korea stood at about 46 in 2003, and it increased more than five times during the last 5 years, 241 in 2008 (Ministry of Education, Science and Technology, 2010). Also, it is expected the growth number of students in the future (Wongrakha, 2010).

Another fact that is neglected is that most of the foreign students in Korea rely on private funding and the numbers of self-financed students has been growing (Korea Education Development Institute, 2008). The study abroad requires the students for a large amount of money, not only the tuition fees, but also living costs according to the attributes in the country. Consequently, the oversea students may need to allocate the spending and saving during long term staying. Especially, living costs in Korea is much more expensive than own country, most Asian countries. As Anderson (1984), and Yu and Kim (2004) stated, the change of residence can affect the people rethink and reorganize their consumption patterns both directly and through intervening factors; consumer lifestyle and stress. The pressure of equate with the spending habit can be the serious issue for the oversea students.

All things considered, this study aims to understand the experiences of Thai students studying in Korea, especially their experiences as consumers in terms of their ways of consuming behavior and the meaning they ascribe to these experiences which are related to the circumstances of Korea. Understanding what Thai students experience as consumers in Korea will shed light not only for the universities and institutions in Korea but also for sending countries as well. At first, this study will review push factors from Thailand and pull factors within Korea to understand the background why Thai students select to study in Korea.

\section{CONTEXTS: PUSH AND PULL FACTORS}

McMahon (1992), and Mazzarol and Soutar (2002) suggested the flow of students internationally results from a combination of push and pull factors. On one hand, push factors operate within the source country and initiate the students' decision to undertake international study. On the other hand, pull factors operate within a host country to make that country relatively attractive to international students (Mazzarol \& Soutar, 2002). These factors are an important framework for understanding the influences that motivate Thai students' selection of Korea.

\section{Push Factors from Thailand}

Thailand's economy growth rate was double digit in the late 1980s, and it became one of the fastest growing economies in the world (Akrasanee, Dapice, \& Flatters, 1991). The country's industrialization and 
economic development fundamentally changed the character of the Thai society, bringing a higher purchasing power, new consumer commodities are available, more materialistic attitudes, emergence of nouveau riches who became rich from real estate business, or stocks. McMahon (1992) suggested that the push model is dependent on the level of economic wealth, the degree of involvement of a home country in the world economy, and the availability of educational opportunities in that country. One of the reasons for the continued demand for international higher education in Thailand is the increase of paying capacity from the individual students and their families. The faster economic growth and the improvement in income levels and standards of living have certainly enhanced the paying capacity for those who seek international higher education. Thailand has experienced a high rate of economic growth (Laird, 2000) and an increase income which enables them to seek education abroad.

In terms of more individual level, family, peers, and student recruitment agencies are reported as the strong push factors in Thailand. Family influence has been extensively reported as a key push factor profoundly affecting the choices of international education (Mazzarol \& Spoutar, 2002; Smart \& Ang, 1993). Most studies mentioned two aspects of family influences: recommendation and financial support (Pimpa, 2003).

On the other hand, Thai people believe that educated people-those holding degree, are those who know everything and receive the trust from others. Those who are educated have jobs which bring honor and have good status. Education is a mean to lift oneself up and out of lower positions (Soupap, 1975). Moreover, Thai people believe that the oversea education is better than study in local. It is a good investment of education and the future for their children. They can namely take an advantage of oversea study means academic qualification. Not only foreign language ability but also the life experience can they obtain during staying (Pimpa, 2003). The oversea study is not the fashion, but it is one of Thais' values.

The tradition of sending the children study abroad in Thailand emerged for long time since late 1990s. In 1885, King Chulalingkorn sent his loyal princes to Germany, England, Russia, and Japan to introduce into welfare of the Thai nation. Later, families in high hierarchy, mostly the government officers' family, sent their children to enhance their knowledge in other countries, and returned to Thailand to get the high official position (Wyatt, 1982). Graduate from oversea country serve the career path, and it is also directly connected with the social status, which is the popular pursuit of all Thai people as it brings honor, gives power, and elevates one to a position where others give respect and homage (Soupap, 1975).

Another push factor could be the popularity of Hallyu and K-pop. Since 1997 the phenomenon of Hallyu or K-pop in Thailand has invented to increase tourism and raise the profile of Korea in Thailand (Kim \& Kim, 2009). The gateway for aspects of Korean culture was broadcasted. These are music, drama, food, fashion etc. It has encouraged many Thai students to undergo higher education program in Korea. In the past, there were only three universities in Thailand which open the department of Korean Language (Noh, 2009). However, according to the demand of the Thai students many universities and institutes provide the course as the minor subjects. Recently, in the working market in Thailand, there is a position requirement from the Korea business investors who are seeking for much manpower qualified by Korean language to work in their business places (Kim, 2005). Consequently, many people are interested more in study Korean as their third language. As such, economic growth, values on education, especially preference to oversee education, and Hallyu fashion encourage Thai students to study Korea.

\section{Pull factor within Korea}

The number of students coming to Korea has grown steadily in recent years, boosted by the Korean government's "Study Korea Project," a drive to globalize local universities by attracting more oversea students. The project, which began in 2004, aims to have 100,000 international students in Korea by 2010 (Ministry of Education, Science and Technology, 2010). 
Table 1. Foreign Students Studying in Korea by Region and Year

\begin{tabular}{lrrrrrrrrr}
\hline & 1990 & \multicolumn{1}{c}{1995} & \multicolumn{1}{c}{2001} & \multicolumn{1}{c}{2003} & \multicolumn{1}{c}{2005} & \multicolumn{1}{c}{2007} & \multicolumn{1}{c}{2008} & \multicolumn{1}{c}{2009} & \multicolumn{1}{c}{2010} \\
\hline Asia & 1,527 & 1,318 & 8,755 & 10,436 & 19,969 & 45,622 & 59,375 & 70,853 & 76,483 \\
Africa & 21 & 34 & 100 & 112 & 184 & 291 & 397 & 587 & 786 \\
Oceania & 15 & 21 & 156 & 128 & 145 & 142 & 178 & 221 & 280 \\
N .America & 547 & 375 & 1,488 & 723 & 1,105 & 1,692 & 2,165 & 2,605 & 3,095 \\
S. America & 77 & 124 & 209 & 127 & 209 & 240 & 278 & 406 & 511 \\
Europe & 50 & 111 & 938 & 788 & 914 & 1,283 & 1,559 & 1,944 & 2,687 \\
Total & 2,137 & 1,983 & 11,646 & 12,314 & 22,526 & 49,270 & 63,952 & 76,616 & 83,842 \\
\hline
\end{tabular}

Educational Statistics Yearbook "1990 2010" (2010.4) 4-year university only

Attracting oversea students in Korea has become important not only for education but also the economy and diplomacy. This program is also directed to greater access to Korean language and culture. The Ministry lists option on a website, organizes oversea study exhibitions, launch events to integrate fully with Korean culture, open preparatory education classes to study Korean language and expand the number of test sites where candidates can sit the Korean proficiency tests. It will also assist universities in opening Korean classes for foreign students so that students from overseas can navigate their way through the cultural obstacles. Moreover, there are large offers by Korea-Thai Governments and Thai-Korea Universities to give the financial aids for students who intend to seek educational opportunities in Korea both in the long term and short term.

These international students will also serve as a driving force in this country, which is suffering from a low birth rate. Especially, in the universities located in suburb area, they have difficulties in recruiting the students. They could not require the reasonable students enrolled, and one of the strategies was looking at outside Korea. They have actively marketed the foreign countries to advertise their educational programs. It is evident the growing number of total universities internationally collaborated partnerships with foreign countries. In 2008, its number is more than 140 (Ministry of Education, Science, and Technology, 2008).

Oversea education has become an important mode for globalization. It became a market-driven activity (Varghese, 2008). If the number of foreign students increases to 100,000 , Korea can earn 160 billion won. In Table 2, we find that most of the foreign students in Korea rely on private funding and numbers of self-financed students has been growing. Scholarships given by the Korean government are much smaller in comparison with other host countries.

To conclude, these pull factors work in conjunction with the push factors mentioned earlier to create the demand for Thai students for study in Korea.

Table 2. Foreign Students by Source of Funds

\begin{tabular}{lrrrr} 
& \multicolumn{1}{c}{2005} & \multicolumn{1}{c}{2006} & \multicolumn{1}{c}{2007} & 2008 \\
\hline Self-paying & $17,599(78.1)$ & $18,221(80.5)$ & $42.273(85.8)$ & $54,934(85.9)$ \\
Invited by Korean government & $388(1.7)$ & $350(1.5)$ & $581(1.2)$ & $837(1.3)$ \\
Invited by university & $2,873(12.7)$ & $3,016(13.3)$ & $3.706(7.5)$ & $3,010(7.8)$ \\
Dispatched by government & $309(1.3)$ & $265(1.1)$ & $511(1.0)$ & $587(.9)$ \\
Others & $1,357(6.2)$ & $772(3.6)$ & $2,199(4.5)$ & $2.584(4.0)$ \\
\hline
\end{tabular}

Korea Education Development Institute. Statistical analysis of education, 2005 2008. 


\section{RESEARCH METHODOLOGY}

\section{Individual Interviews}

In order to understand the experiences of Thai students as consumers in studying Korea, individual interviews were conducted. A total of 5 participants were identified through personal relationship and several University Language Center. Even though more participants were identified, some of them were rejected to interview the research. So it ended up with 5 participants. Before conducting the interviews, they were fully briefed of the aim of the research and its significance in helping to improve the understanding of Thai students in universities in Korea. Also, they are informed that the interviewing process was recorded, it guarantees the confidentiality, and they can quit anytime for any reasons. The interviews were conducted from August 11, 2010 to October 29, 2010, and each interview took about 2 hours. Each participant was given the option to be interviewed in language, and they all preferred Thai. The interviews were transcribed, and translated into English.

The interview questions were unstructured in order to make them freely as possible. The interviews were conducted around the essential experiences as consumers living in Korea. More specifically, the essence of experiences as consumers, the meanings of consumption in everyday life in Korea, the characteristics of the current consumption behavior, and any changes in consumption behavior compared to living in Thai. All these questions are summarized to the last question, such as what these whole experiences mean to you.

\section{Research Participants}

The participants were 20 to 30 years old, and have studied in Korea from 11 months to 21 months. Gift, 25 female student, has graduated from Thailand. She has studied Korean in Thailand because she was interested in Korean pop singers. Consequently, she decided to come to Korea to learn Korean more systematically. At first, she was planning to stay in Korea for 6 month, but she has extended the staying to acquire more knowledge about Korea and Korean because she thought that it could be a good ladder for her career in the future. Since she was young, she has been staying with her elder sisters. Her sisters gave her allowances, and she never felt that she controlled her own spending. Now, she was spending money on her own decision, and feels that the money is under her control, not her sisters.

Sai (20) is an undergraduate student who got scholarship from the university in Korea. She comes from the countryside of Thailand. She was only 18 years old when she first steps to Korea. She told that she was one of shopping lovers since she was in Thailand. She always looks for brand name products which her high school classmates mostly use. She always saves money from daily allowances in order to get the products she wants. However, she feels that the living expense itself affects her life in Korea, especially because she has lived in the countryside of Thailand.

Lew (25) just graduated from the university in Thailand. She has studied Korean in Thailand, and worked as a part-time in Thailand, translating Korean movies subtitles. She came to Korea to explore the new experiences of oversea and her Korean ability. She thought that if she would like to get a job with high income in Thailand, coming to Korea could be a good investment. Lew is never interested in fashion in Thailand. However, since she moved to Korea, she acknowledges that the appearance is the most importance.

Pan is 19 years old. He got the scholarship from the university in Korea after he failed to enter the university in Thailand. He hopes to study abroad because he wants to live far away from his family. His family always pushes him to be more ambitious, and it makes him run away as far as possible from the surrounding pressure. And the chance of coming to Korea was there.

Jasmin, 30, has worked for 9 years after graduation in Thailand. She has the experiences visiting Korea for vacation and business before, and studied Korean in Thailand. However, she felt tired of working in Thailand, and decided to study in Korea. That was a big change of her life. She is a kind of society person because of the characteristics of her previous job. So she usually spends her time and money with her social activities in Korea.

The general characteristics of the research participants are summarized as $<$ Table $3>$ 
Table 3. The General Characteristics of the Research Participants

\begin{tabular}{|c|c|c|c|c|c|}
\hline Name (Age) & Gender & Duration of Stay & Status & $\begin{array}{l}\text { Source and Amount of lncome } \\
\text { (per month) }\end{array}$ & Expenditure \\
\hline Gift (25) & Female & 1.6 years & Language Center student & $\begin{array}{l}\text { Sister } \\
500,000 \text { won }\end{array}$ & 500,000 won \\
\hline Sai $(20)$ & Female & 2 years & Undergraduate Student & $\begin{array}{l}\text { Scholarship (living cost) } 200,000 \text { won } \\
\text { Parents } 300,000 \text { won }\end{array}$ & 500,000 won \\
\hline Lew $(25)$ & Female & 1.6 years & Language Center student & Parents 500,000 won & 500,000 won \\
\hline $\operatorname{Pan}(20)$ & Male & 1.9 years & Undergraduate student & Scholarship (living cost) 800,000 won & $\begin{array}{l}550,000 \text { won } \\
\text { (saving } 250,000 \text { ) }\end{array}$ \\
\hline Jasmin (30) & Female & 11 months & Graduate student & $\begin{array}{l}\text { Ex-company } 1,400,000 \text { won } \\
\text { Part-time job } 480,000 \text { won }\end{array}$ & 500,000 won \\
\hline
\end{tabular}

\section{Text Analysis}

This research used the phenomenological reflection of van Manen (1990) which is the wholistic and selective approach to seek the essential meanings of the experiences. In the wholistic approach, the text as a whole is attended, that is what sententious phrase may capture the fundamental meaning or main significance of the text as whole? And meaning by formulating such a phrase is expressed. In the selective approach, what statements or phrases seem particularly essential or revealing about the experience is highlighted. Through reading a text several times and ask those questions, it is noted that certain experiential themes recur as commonality in the various descriptions, and then hold on to these themes by lifting appropriate phrases or by capturing in singular statements the main thrust of the meaning of the themes.

Once transcript themes have been identified, then these themes are reflected in follow-up conversations in which both the researchers and the research participants. In attempting to interpret the significance of the preliminary themes, and weigh the appropriateness of each theme, it is eventually uncovered thematic aspects of 'Thai students' experiences as consumers in Korea.

\section{THAI STUDENTS' EXPERIENCES AS CONSUMERS}

\section{Price Consciousness: Survival itself is too much}

At the first stage of coming to Korea as students, all participants in the study said that they are surprised because of high living expense in Korea which totally differs from Thailand. The most stressful thing is the price of meals since it is almost twice or three times of Thailand. They can spend the same amount of money for weeks in Thailand.

"In the first three months, frankly, I was shocked about the food because in Thailand even we eat in the department store. The price is about $100 \mathrm{THB}, 50$ or 60 , right? But here even in front of the school, Tokpokki, is $60 \mathrm{THB}$, but it's so small plate." (Lew)

"First time I felt that it was expensive. At the early stage I didn't want to spend money or buy anything. A cup of coffee is 100THB. It's so expensive. A meal is about 70THB. Maybe the currencies are different. We just pay for what makes us survive. And we could not save at all." (Pan)

Not only price of foods, but also the totally differences of weather between Thailand and Korea impacts much to the Thai students. Since Thailand is a tropical country, it is not necessary to purchase clothing so often. However, due to the frequent season change, they need to spend money for new clothes for every season to protect them from the changing weather.

"It affects me so much. I hate cold weather. In Thailand there's always hot, but here is so cold. I need gloves, coat, winter cap etc. That means I need to spend more for those which I can't use in Thailand. The expense is increasing. Yes, I think the weather here affects my buying behavior." (Gift) 
"I didn't frequently buy clothes, but here because of the weather, I need spend much money for the overcoat, booths which I can't wear it in Thailand." (Jasmin)

Consequently, they have become more conscious of prices of goods. Price consciousness refers to the degree to which the consumer focuses exclusively on paying low prices (Lichtenstein, Ridgway, \& Burton, 1993). The participants in the study said that they seek low price store, use coupon-redemption behavior, and price maven, a desire to be informed of low price information for other Thai students, regardless of quality of goods.

"When I was in Thailand, I usually bought brand name or very good quality of products, and normally I went to the department store. But now I just think the quality does not matter for me anymore. I do now prefer a low price." (Sai)

"In Thailand I mainly buy things in the department store, but now if I want to buy some clothes, I prefer to go to Dongdaemun or Shinshon where I can find a cheap price, but o.k. quality. Moreover, I can ask for discount." (Jasmin)

"The price in Korea is twice of Thailand's. I download discount coupons from the internet, whenever I go to shopping, to eat out or even to see movies. It helps me to reduce some expense" (Lew)

Culture shock, distance from family and language barriers are issues that many international students face while studying in Korea, but financial pressure to even manage basic goods such as decent meals and clothing can be an even bigger obstacle. Having to worry about basic necessities is the most extreme form of financial problems. Moreover, the exchange rate between Korean won and their domestic currencies could be high. A small amount of money to Korean can be significant to the Thai students.

Furthermore, food and clothing is more than a means of sustenance; they are also a key cultural expression (Penaloza, 1994). Eating the Thai food may provide them with a taste of home and serve to reaffirm ties to their culture of origin. However, they mostly make do with the instant food or skip a meal just because of financial pressure. Thai students in this study accept that it is an unavoidable situation, and they seem to be consider food and clothing as a merely means of sustenance.

\section{Control my own budget, control my own life}

Meanwhile, the participants in this study use their consumer behavior as a mechanism to feel some degree of freedom. And Living environments make it possible no matter what source of money is. When they were in Thailand, they were living with their parents or guardians who are powerful to control their expenses and consumption. For example, they seldom purchase anything and request anything whatever they want to buy. It is to say that the previous consumption behavior was framed by their parents.

"When I was in Thailand, whenever I wanted go shopping, itís always with mom. I told her that I wanted this shirt, she told me right away, "No, it's not suit you, it's too expensive, blah, blah. I can't buy whatever I want. Everything is in her hands. Now, I feel that itís my money. I feel happy and I am proud that I am free from parents at the age of 19. It's so cool." (Pan)

"My sister transferred to my bank account in Korea. So now, I am the only one who is controlling that money. Yes. I know actually it's hers. But I started purchasing everything I want." (Gift)

It is hard to be independent while children are under their parents' roof. Especially, parents set down financial rules before their children can spend a cent. And many children and their parents have different ideas about what these rules should be. Generally, parents play an active role as a consumer socialization agent (Solomon \& Rabolt, 2009). They deliberately try to instill their own values about consumption and money in their children. The Thai students in this study have been constantly restricted by their parents in the area of consumer behavior 
when they were in Thailand. However, life on campus in Korea is the best route to freedom. The participants in the study feel that they can control their own consumption behavior, and it brings the power of control of their own lives. They have a strong desire to control their own lives, and they can acquire this sense of control through their consumption even though the money comes from their parents. Followings are shown how they are proud of their decisions.

"I experienced something from the consumption in Korea. It's some kind like the limit of expense. I don't know until when my mom is able to support me. So I need to do something for my future. So, I decided to play the stock in Thailand." (Sai)

"Until now, I have been saving about 3 million won. I have to register the language center at 1.5 million, though. But if I pass the test, I can apply a job here more easily, and the scholarship will be added 100,000 won more. It's a good investment for my future. And I am proud of myself that I save the money, and invest it for my future. It feels so good." (Pan)

Life status change including changing residence, getting married or having a child has its own unique requirements for change in consumption pattern (Anderson, 1984). The transition to adulthood most of the participants in this study are experiencing can be a period of growth and accomplishment through controlling their own budget.

\section{Socialization into a Korean Consumer Culture}

Korea is one of the countries with fashion merchandise varying in different styles, designs and prices, available at various shops and outlets. Thus facilitates and encourages consumption among Thai students. It makes them consume excessively, and as a result it brings them a financial problems.

"I seldom bought this kind of stuff in Thailand. I am not a person who is interested in fashion. I have never put make up. I don't like well dress. But here, everyone is dressing very good, so I want to be like them. When I was in Thailand, I can go out with the pajamas, but it is impossible here." (Lew)

"Korean fashion is trendier than Thai's. In Thailand, all clothes look same, but here, it's so tempting. The fashion here is so cool. It attracts me to buy. I never bought this kind of stuff. I have changed to spend more about cloth, fashion items. I never go to the cosmetic shop, but now I enjoy going the shop." (Sai)

Living alone in another country could cause Thai students more stressful. It could impact their behavior to purchase unnecessary items more to release the stress. They are likely to be influenced from the consumer culture pervaded in Korea. The buying can make them release from the loneliness they are facing.

"Sometimes I feel lonely. If it's so, I just go to Kosney, and buy some little cute stuff like candles. I don't know the reason, but I just feel that I want to buy, buy, and buy. It helps me from my bad emotions, and it helps." (Gift)

"When I feel lonely, I just go right away to the cloth shops in front of the school, and buy a lot of clothes." (Sai)

Moreover, they feel that they need more money for the social activities which is one of the big parts of the expenses. To keep the social relationship and balance their expense, they have to control the frequency of going out with their friends.

"I got many groups of friends. So every time I hang out with them like at cinemas, restaurants, bars. I need to spend a lot of money. Sometimes it is about half of my allowances/" (Jasmin)

"I think if I want to have Korean friends here, I need to go out with them, eat with them. That costs too much. It is a kind like an exchange between friends and money." (Sai)

Age was one of the most important factors determining whether living abroad experience could result in any consumer behavior. According to $\mathrm{Yu}$ and Kim (2004), younger peoples seemed to have absorbed the host cultures more easily and to a 
larger extent. In that sense, these study participants were relatively young when they came to Korea, and consumer acculturation took place much more easily and faster. They are sensitive their appearance and interested in making friends at the height of their lives. However, some people rather did not worry about the latest fashion or what others think about their appearance while staying in another country. So the experiences of Thai students could be not only characteristics of their age, but also those of Korean consumer culture.

\section{CONCLUSION AND DISCUSSION}

In this study, Thai students as oversea students in Korea expressed their experiences as consumers while living alone in Korea. Most of the students pointed that they had a hard time to get used the expensive living costs and limited social activities due to financial burden. It made them price conscious consumers. Thai students in this study reported that they were much more brand conscious consumers rather than price conscious consumers. That is implicit in the relationship between quality and price.

Meanwhile, they were easily imbued with Korean consumer culture. Ironically, it sometimes caused compulsive consumption in order to release the stress. The ways in which Thai students consume were much more complex than simply buying or not buying. Once here, Thai students purchased and used many products and services associated with Korean culture. Yet many aspects of their new consumer environment in Korea, such as living costs, frequent social gatherings drove them to the wall. They sometimes feel pressure to spend, resist, or adapt to the new consumer environment.

Living abroad for a certain period of time can affect the people rethink and reorganize their consumption patterns both directly and indirectly (Yu \& Kim, 2004) because consumption is related to culture and cultural meanings transferred to consumer goods and individual consumers (McCracken, 1986). In this sense, Thai students' living experiences in Korea made them change their perception and behaviors as consumers. For instance, they become more interested in fashion, cosmetics, accessories etc under the limited financial resources. Furthermore, living abroad by oneself is a multi-faceted experience, so the participants in this study tend to re-establish their self-esteem through planning their spending and saving.

Globalization in the recent era has increased the opportunity to live abroad for an extended period of time including student studying abroad. However, unlike tourists, they usually stay in the new culture long enough that they are expected to get acquainted with and make adjustments to the host culture. At the same time, in contrast to immigrants, they are also expected to retain the links to their home culture and make re-adjustment when they return. Along with the quantitative increase, universities and government should focus on improving the selection of candidates, enhancing Korean academic standards, and thereby improving the living conditions for international students in order to make them return well to their countries after finishing their studies.

The process by which Thai students decide to study in Korea and how they live as temporary residents in Korea as foreigners are complex and underinvestigated. Although the push and pull framework has been used to describe the process, it only identified some of the larger social, political, and economic factors. Even though it is not a focus of this study, the way these forces interact within the individual is speculative. In order to understand how they live in different culture by themselves, this process should be more clarified. Beyond the decisions of these students, much is unknown regarding their everyday lives not only as students but also as consumers, friends, and neighbors as well. As such, more empirically based research is needed to better understand and address those peoples who are members of our society.

The foreign students in Korea are not an amorphous mass with undifferentiated characteristics. However, few studies have attempted to explain considerable national differences from other countries. This study shows that it has become apparent that the experiences of international students studying in Korea are more meaningful if a concerted analysis of 
culture of origin is considered. Since this study has only focused on the meaning of consumption in everyday life in Korea and relatively small number of participants, its implications are open to further questions. For instance, further research should consider more specific aspects such as consumer lifestyle, consumption pattern, or consumer values. Or more controlled methodological approach to examine how living abroad experience could bring consumer behavior. In conjunction with this research, experiences as consumers of Thai students in Korea will be clearer.

\section{REFERENCES}

Ahn, Y. J. (2009). A study on incoming international students' immigration process and background. Journal of the Economic Geographical Society of Korea, 12(4), 344-363.

Akrasanee, N., Dapice, D., \& Flatters, F. (1991). Thailandis export-led growth: Retrospect and prospects. Thailand Development Research Institute Foundation. Policy Study No. 3. (http://www.tdri.or.th/en/ pdf/ps3.pdf).

Anderson, A. (1984). Life status change and change in consumer preference and satisfaction. Journal of Consumer Research, 11(3), 784794.

Cui, J. H. (2008). A study on the school and social life adjustment of Chinese students in Korea. Journal of Adolescent Welfare, 10(1), 115-138.

Kang, K. (2009). Internationalization of higher education in South Korea. Paper presented at the International Conference on Higher Education Research and Development.

Kim, H. K. (2005). Korean wave in Thailand: Analysis and evaluation. 12, 111-148.

Kim, S. S., \& Kim, M. J. (2009). Effect of Hallyu cultural products in Thai society on enhancement of Korean national image and intention to visit. Korean Journal of Tourism Research, 23(4), 101-125.

Korea Education Development Institute (2008). Statistical analysis of education, 2005 2008.

Laird, J. (2000). Money politics, globalization, and cri- sis: The case of Thailand. Singapore: Graham Brash. Lee, S. B., \& Kim, D. W. (2009). Exploring influential factors on cultural adaptation of Chinese students in Korea. Speech and Communication, 11, 47-79.

Levin, J. S. (2001). Public Policy, Community Colleges, and the Path to Globalization, Higher Education, 42(2), 237-261.

Lichetnsteinm, D. R., Ridgway, N. M., \& Burton, S. (1993). Price perceptions and consumer shopping behavior: A field study. Journal of Marketing Research, 30(May), 234245.

Lim, C. H. (2009). Acculturative stresses and adjustment elements of Chinese students' studying in Korea. Journal of Korean Living Science Association, 18(1), 93-112.

Mazzarol, T., \& Soutar, G. N. (2002). "Push-pull" factors influencing international student destination choice. The International Journal of Educational Management, 16(2), 82-90.

McMahon, M. E. (1992). Higher education in a world market: An historical look at the global context of international study. Higher Education, 24(4), 466-482.

Ministry of Education, Science, and Technology (2008). Educational Statistics Yearbook.

Ministry of Education, Science and Technology (2010). Educational Statistics Yearbook.

Noh, M. Y. (2009). Korean language education in Thailand. The Research on Korean Language and Literature, 53, 97-121.

Penaloza, L. (1994). A critical ethnographic exploration of the consumer acculturation of Mexican immigrants. Joumal of Consumer Research, 21(1), 3254.

Pimpa, N. (2003). The influence of peers and student recruitment agencies on Thai students choices of international education. Journal of Studies in International Education, 7(2), 178-192.

Smart, D., \& Ang, G. (1993). Opportunity for Australian higher education: A pilot survey of Singapore. Perth: Asia Research Center on Social, Political and Economic Change, Murdoch University.

Solomon, M. R., \& Rabolt, N. J. (2009). Consumer behavior. New Jersey: Pretince Hall. : 
Song, W. Y., \& Li, N. (2008). Chinese students' early psychological adaptation according to their acculturation type. The Korean Journal of School Psychology, 5(2), 159-173.

Soupap, S. (1975). Thai society and culture. Chilaongkorn University.

Yu, H. K., \& Kim, C. J. (2004). Influence of living abroad on people in general and their dothing style: the case study of Korea. Journal of Korea Society of Clothing and Textiles, 28(12), 1644-1654.

Van Manen, M. (1990). Researching lived experiences: Human science for an action sensitive pedagogy.
NY: The State University of New York.

Varghese, N.V. (2008). Globalization of higher education and cross-border student mobility. UNESCO.

Wongrakha, P. (2010). Korea studies: New trend in Eastern Asia. http:/social.obec.go.th/node/15(posted on March 20, 2010).

Wyatt, D. K. (1982). Thailand: A short history. New Haven: Yale University.

Received March 31, 2011

Revised June 7,2011

Accepted June 8, 2011 